\title{
Headache attributed to aeroplane travel: the first multicentric survey in a paediatric population affected by primary headaches
}

\author{
Debora De Carlo ${ }^{1 \dagger}$, Irene Toldo ${ }^{1 \dagger}$, Agnese Maria Tamborino ${ }^{2}$, Barbara Bolzonella ${ }^{1}$, Maria Giuseppina Ledda ${ }^{3}$ \\ Lucia Margari ${ }^{4}$, Vincenzo Raieli ${ }^{5}$, Margherita Santucci ${ }^{6}$, Vittorio Sciruicchio ${ }^{7}$, Angelo Vecchio ${ }^{8}$, Sergio Zanini ${ }^{9}$, \\ Stefano Sartori ${ }^{1}$, Michela Gatta ${ }^{1}$, Alberto Verrotti ${ }^{2}$ and Pier Antonio Battistella ${ }^{1 *}$
}

\begin{abstract}
Background: This multicentric survey investigates the prevalence and characteristics of Airplane Headache in children affected by primary headaches.

Methods: Patients with symptoms of Airplane Headache were recruited from nine Italian Pediatric Headache Centres. Each patient was handed a structured questionnaire which met the ICHD-III criteria.

Results: Among 320 children suffering from primary headaches who had flights during their lifetime, 15 (4.7\%) had Airplane Headache, with mean age of 12.4 years. Most of the patients were females (80\%). The headache was predominantly bilateral (80\%) and localized to the frontal area (60\%); it was mainly pulsating, and lasted less than $30 \mathrm{~min}$ in all cases. Accompanying symptoms were tearing, photophobia, phonophobia in most of the cases (73.3\%). More than $30 \%$ of patients used medications to treat the attacks, with good results.

Conclusion: Our study shows that Airplane Headache is not a rare disorder in children affected by primary headaches and highlights that its features in children are peculiar and differ from those described in adults. In children Airplane Headache prevails in females, is more often bilateral, has frequently accompanying symptoms and occurs at any time during the flight.

Further studies are needed to confirm the actual frequency of Airplane Headache in the general pediatric population not selected from specialized Headache Centres, with and without other concomitant headache condition, and to better clarify the clinical characteristics, pathophysiology and potential therapies.
\end{abstract}

Keywords: Headache, Aeroplane travel, Airplane, Primary headaches, Children, Pediatric headache, ICHD-III

\section{Background}

Headache disorders in children and adolescents are common disabling problems with a significant impact on the quality of life of both children and parents $[1,2]$.

Airplane headache $(\mathrm{AH})$ is a relatively rare headache disorder associated only with airplane travel; in particular pain begins during taking off or landing or both [3].

The first adult case of AH was reported in 2004 [4]. Its prevalence is unknown and the underlying pathophysiology

\footnotetext{
* Correspondence: pierantonio.battistella@unipd.it

${ }^{\dagger}$ Debora De Carlo and Irene Toldo contributed equally to this work.

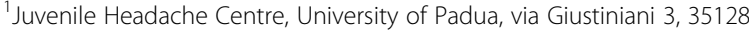

Padua, Italy

Full list of author information is available at the end of the article
}

is uncertain, although sinonasal barotrauma has been proposed [4-6].

In 2013 Mainardi et al. [7] collected clinical data of 75 patients with symptoms suggestive of $\mathrm{AH}$ and proposed provisional diagnostic criteria.

There has been a steadily increase in the number of reported cases in the following years: up to now, 275 adult cases have been described in the literature [7-20] and, recently, two systematic reviews have been published [21, 22]. Most of the known cases of AH are young males. In all cases, symptoms are highly stereotyped. The pain is typically reported as severe and may be described as jabbing, stabbing, or pulsatile in quality. It is usually unilateral and localized to fronto-orbital and 
fronto-parietal regions. The headache is short-lived, lasts less than $30 \mathrm{~min}$, and occurs exclusively in relation to airplane travel (most frequently during airplane descent). Accompanying symptoms are usually absent.

So far only 5 cases within the pediatric age group have been described [23-25].

The aim of our study is to investigate the prevalence and characteristics of $\mathrm{AH}$ in a large group of children suffering from primary headaches, taking into account experts' opinion about the pediatric secondary headache diagnostic criteria of ICHD-III beta [26].

\section{Patients and methods}

This study is a multicentric pediatric cohort study. Patients with symptoms suggestive of $\mathrm{AH}$ were recruited from 9 Italian Pediatric Headache Centres.

During the study period, all patients were solicited to take part in the study. Following an explanation about the study purposes, each patient was handed a structured questionnaire, aimed at obtaining all the relevant information that could clinically distinguish this peculiar disorder. The questionnaire met the ICHD-III criteria [27].

The inclusion criteria were:

A. At least two episodes of headache fulfilling criterion $\mathrm{C}$.

B. The patient is travelling by aeroplane.

C. Evidence of causation demonstrated by at least two of the following:

1. headache has developed during the aeroplane flight

2. either or both of the following:

a) headache has worsened in temporal relation to ascent following take-off and/or descent prior to landing of the aeroplane.

b) headache has spontaneously improved within 30 min after the ascent or descent of the aeroplane is completed.

3. headache is severe, with at least two of the following three characteristics:

a) unilateral location.

b) orbitofrontal location.

c) jabbing or stabbing quality.

D. Not better accounted for by another ICHD-3 diagnosis.

E. Age $\leq 18$ years.

The structured questionnaire was composed of 32 questions and included two sections: medical history and details of nature of $\mathrm{AH}$.

A total number of 727 children participated in this survey. The questionnaire was completed by 637 subjects.

Most of the cases were females (364 females, 273 males). The mean age of patients was 11.3 years (range 3.1-18.0).

\section{Results}

Age at onset

Among 320 patients who flew during their lifetime, only $15(4.5 \%)$ had AH. Most of the cases were females (12 females, 3 males). The mean age at recruitment was 12.4 years (range 8.2-16.0); the mean age at headache onset was 7.2 years (range 3.1-11.1).

\section{History of coexistent primary headaches}

A specific section of the questionnaire focused on the possible coexistence of a primary headache, according to the ICHD-III [27]. In the total study population $(n=637)$, the most commonly associated primary headaches were migraine $(n=456 ; 71.6 \%)$ and tension-type headache $(n=137 ; 21.5 \%)$. In 29 patients $(4.5 \%)$ two different coexistent primary headaches could be diagnosed; no patient reported symptoms suggestive of cluster headache (Table 1).

The neurological examination was unremarkable. Basic biochemical and hematologic tests and brain magnetic resonance imaging revealed no abnormalities.

Twelve children (80\%) with AH suffered also from migraine. Two patients (13.4\%) with $\mathrm{AH}$ had also tension-type headache. One patient (6.7\%) suffered from new daily persistent headache (Table 2 ).

\section{Upper respiratory tract disorders}

A personal history for allergy was reported by 3 patients (20\%), and for sinus infection by 3 patients $(20 \%)$. No patients had symptoms and/or signs related to inflammatory sinus disorders following an ENT specialist evaluation, performed immediately after the attack.

\section{Clinical features of airplane headache}

The clinical characteristics of $\mathrm{AH}$ were quite peculiar.

\section{First episode}

Seven children (46.7\%) presented $\mathrm{AH}$ since the first flight experience.

Two patients (13.3\%) flew 3-6 times per year, and seven patients $(46.7 \%)$ flew less than one per year.

Table 1 Classification of headaches in patients

\begin{tabular}{lll}
\hline Headache type & $\mathrm{N}$ & $\%$ \\
\hline Migraine without aura & 368 & 57.8 \\
Episodic tension-type headache & 82 & 12.9 \\
Migraine with aura & 74 & 11.6 \\
Chronic tension-type headache & 55 & 8.6 \\
Migraine + tension-type headache & 29 & 4.5 \\
Other primary headaches & 15 & 2.3 \\
Chronic migraine & 14 & 2.2 \\
Total & 637 & 100 \\
\hline
\end{tabular}


Table 2 Concurrent primary headaches in $\mathrm{AH}$ patients

\begin{tabular}{lll}
\hline Headache type & $\mathrm{N}$ & $\%$ \\
\hline Migraine with aura & 7 & 46.7 \\
Migraine without aura & 5 & 33.3 \\
Episodic tension-type headache & 1 & 6.7 \\
Chronic tension-type headache & 1 & 6.7 \\
New daily persistent headache & 1 & 6.7 \\
Total & 15 & 100 \\
\hline
\end{tabular}

\section{Consistency of attacks}

In 7 children (46.7\%) the same type of headache recurred consistently on separate flights; for those patients the pain started exclusively during landing in two, both during take-off and landing in three, during take-off in one and during cruising in one. The attacks occurred in more than $50 \%$ of flights only in one child $(n=1 / 15$, $6.7 \%)$; for this patient the pain started only during take-off. The attacks occurred in less than $50 \%$ of flights in 3 patients (20\%): exclusively during landing in two and also during cruising in one. In 4 cases $(26.7 \%)$ the attacks were occasional and unpredictable. One patient reported the occasional occurrence of attacks during cruising only in the case of short-haul flights.

\section{Timing}

$\mathrm{AH}$ can occur at any time during the flight. More specifically, in three patients (20\%) the attacks occurred exclusively during landing; in three patients (20\%) AH started only during take-off. Five patient (33.5\%) reported headache onset during cruising. In three patients (20\%) $\mathrm{AH}$ started during both take-off and landing, and in one patient during cruising and landing (Table 3). No patients reported the possible difference in altitude between the arrival and departure airport as potential aggravating or trigger factors.

\section{Duration}

The duration was less than $30 \mathrm{~min}$ in all patients.

\section{Intensity}

The pain intensity was defined as severe by 10 (66.7\%), moderate by 3 (20\%), and mild by $2(13.3 \%)$ patients.

Table 3 Headache onset with respect to flight timing

\begin{tabular}{lll}
\hline & Female $\mathrm{n}(\%)$ & Male $\mathrm{n}(\%)$ \\
\hline Only during landing & $3(20)$ & 0 \\
Only during take-off & $1(6.7)$ & $2(13.3)$ \\
During cruising & $4(26.7)$ & $1(6.7)$ \\
During both landing and take-off & $3(20)$ & 0 \\
During both cruising and landing & $1(6.7)$ & 0 \\
Total & $12(80)$ & $3(20)$ \\
\hline
\end{tabular}

\section{Quality of pain}

Quality of headache was most frequently defined as pulsating (8 cases, $53.6 \%$ ). Other definitions were: pressing in $4(26.7 \%)$, tightening in $3(20 \%)$ patients.

\section{Localization of headache}

In the majority of patients $(12 / 15,80 \%)$ the pain was bilateral. In the remaining 3 cases (20\%) headache was unilateral; in these cases, the pain constantly recurred on the same side throughout the different attacks in two cases, while in one case $(6.7 \%)$ the pain occurred on the opposite side in subsequent flights. The pain was more frequently localized to the frontal region $(9 / 15,60 \%)$. In three subjects $(20 \%)$ the pain spread to the whole head.

\section{Emotional impact}

Only three children (20\%) were concerned with the fear of suffering from a further attack and therefore were negatively predisposed for future flights. Among these subjects, $2(13.3 \%)$ continued to fly with anxiety and/or worry; one $(6.7 \%)$ decided to fly only if strictly necessary.

\section{Accompanying symptoms}

These were reported by 11 patients (73.3\%): tearing, photophobia, phonophobia. No conjunctival injection, nausea, vomiting were reported.

\section{Self-administered manoeuvres}

Two patients (13.3\%) performed one spontaneous maneuver in order to decrease the intensity of the attacks and to obtain some relief. The self-administered maneuvers were: pressure on the pain site and bracelet. One patient reported a reduction of pain intensity.

\section{Pharmacological treatment}

Ten patients $(66.7 \%)$ did not take any drugs. The remaining 5 patients (3/5 females) used the following medications: acetaminophen $(15 \mathrm{mg} / \mathrm{kg})$, ibuprofen $(10 \mathrm{mg} / \mathrm{kg})$ and ketoprofen $(1.5 \mathrm{mg} / \mathrm{kg})$ were taken within few minutes after the headache onset, with rapid relief (Table 4).

\section{Discussion}

The present study was performed on a selected population affected by primary headaches referring to 9 Italian Pediatric Headache Centres and described in details the clinical features of 15 children suffering from brief headache during airplane travel. The clinical features of $\mathrm{AH}$ in our pediatric population were quite peculiar and differed from those described in adulthood [7-20].

Even though it is not possible to directly compare these data with those on $\mathrm{AH}$ adults recruited from the general population, it seems that $\mathrm{AH}$ features significantly differ between the adult and the child population 
Table 4 Demographic characteristics and clinical reports of the $\mathrm{AH}$ patients

\begin{tabular}{llllllll}
\hline Subject no & Gender & Age (year) & $\begin{array}{l}\text { Duration of AH } \\
\text { (minutes) }\end{array}$ & $\begin{array}{l}\text { Intensity } \\
\text { of pain }\end{array}$ & $\begin{array}{l}\text { Quality } \\
\text { of pain }\end{array}$ & $\begin{array}{l}\text { Localization of } \\
\text { the headache }\end{array}$ & $\begin{array}{l}\text { Pharmacological } \\
\text { treatment }\end{array}$ \\
\hline 1 & F & 12.6 & 30 & 5 & Pressing & Temporal, bilateral & No \\
2 & F & 9.7 & 30 & 2 & Pulsating & Frontal, unilateral & No \\
3 & M & 10.5 & 20 & 8 & Pulsating & Frontal, bilateral & No \\
4 & F & 12.8 & 30 & 4 & Pressing & Frontal, bilateral & No \\
5 & F & 8.2 & 20 & 9 & Pulsating & Frontal, bilateral & Yes, acetaminophen \\
6 & M & 11 & 30 & 1 & Pulsating & Frontal, bilateral & Yes, acetaminophen \\
7 & F & 15.5 & 20 & 8 & Pressing & Frontal, bilateral & No \\
8 & F & 11 & 15 & 8 & Pressing & Diffuse, bilateral & No \\
9 & F & 16 & 25 & 6 & Pulsating & Frontal, bilateral & No \\
10 & F & 14 & 25 & 8 & Tightening & Temporal, bilateral & No \\
11 & F & 12 & 20 & 9 & Pulsating & Diffuse, bilateral & Yes, ketoprofen \\
12 & F & 16 & 30 & 8 & Pulsating & Frontal, bilateral & No \\
13 & F & 15 & 30 & 9 & Pulsating & Frontal, bilateral & No \\
14 & M & 9 & 30 & 7 & Tightening & Diffuse, unilateral & Yes, acetaminophen \\
15 & F & 12.5 & 30 & 8 & Tightening & Occipital, unilateral & Yes, ibuprofen \\
\hline
\end{tabular}

in terms of several clinical features (intensity, distribution of pain, presence and type of accompanying symptoms, male to female ratio, etc). $\mathrm{AH}$ is strictly unilateral in the vast majority of adult cases, its phenotype resembles somehow cluster headache [7]. Moreover, only 20\% of the pediatric patients presented a negative predisposition to future flights compared to $80 \%$ of the adult patients [7] and no one among the pediatric patients appeared to have restlessness or anxiety during the attack, maybe due to the less intensity of the pain. Children showed less frequently concern for subsequent airplane travel maybe for a reduced memory of the painful experience, for the lower intensity of pain and for a greater curiosity for future airplane travels. Moreover, differently from adults [7], no pediatric patients presented an easily recognizable postictal long-lasting mild headache phase after the AH acute attack.

All our patients suffered from at least one type of primary headache, as they were recruited in specialized pediatric Headache Centres. Only 20\% of adults reported in the literature suffered from a concomitant primary headache [5-21]. Interestingly, we have found a relevant association between $\mathrm{AH}$ and migraine with aura. Baldacci et al. [10] reported a patient with $\mathrm{AH}$ also affected by migraine with aura: this primary headache is more rare compared to migraine without aura and episodic tension-type headache in the pediatric population. Therefore, the association between $\mathrm{AH}$ and migraine with aura does not seems to be incidental and deserves further epidemiological studies to better understand the etiopathogenetic mechanisms of this association.
In half of our $\mathrm{AH}$ cases, the first attack was concomitant with the first flight and in $46.7 \%$ of them occurred during each flight. In adult population the first $\mathrm{AH}$ during the first flight occured only in $14 \%$ of cases; that is a significant difference. It is likely that in the pediatric population, the headache attack during the flight warns the parents and therefore it is reported more frequently since the first attack.

The sex ratio was different for pediatric $\mathrm{AH}$ compared to adults [7-20] and was skewed toward females $(80 \%)$ in our young patients. In adult population, the $\mathrm{AH}$ was unilateral and it was localized to the fronto-orbital area [7-20]. The quality of the headache was often defined as jabbing, stabbing and sharp [7-20]. Signs like tearing, conjunctival injection, nausea, vomiting, photophobia, phonophobia were observed rarely ${ }^{7-20}$, while in our study population some of them (tearing, photophobia, phonophobia) were reported by the majority (73.3\%) of patients.

Even though the pain was intense in most cases, only one third used analgesics both in children (33.3\%) and in adults (38\%) [7-20, 23-25].

Two patients performed one spontaneous maneuver to reduce the pain intensity and to obtain some relief, similar to the maneuvers carried out by patients with migraine, tension-type headache and cluster headache, as previously reported [25].

To the best of our knowledge, so far only 5 pediatric AH patients have been reported in the literature: in 2008 Mainardi et al. [23] described the first pediatric patient with $\mathrm{AH}$; in 2010 Ipekdal et al. [24] described three pediatric $\mathrm{AH}$ cases aged between 12 and 14 years; the fifth case was reported in 2015 [25]. 
In the study of Ipekdal et al. [24], nasal mucosal inflammation, adenoidal and tonsillar hypertrophy and sinusitis were the pathophysiological mechanisms found to be responsible for $\mathrm{AH}$. In all the 3 patients, $\mathrm{AH}$ has been solved by treating the underlying disease. In fact, they experienced other airplane travels and reported that they performed headache-free landings without any complication after the treatment.

In our study three children had a past history of sinus infections but none had any clinical evidence of an active sinus disorder during $\mathrm{AH}$ attacks.

Comparing the previously reported 5 cases with our series, we found that quality and intensity were similar, while site of pain was previously reported as unilateral [23-25], differently from our cases. A recent research article confirmed that headache caused by airplane travel is not necessarily unilateral, the description of headache may be not specific and the past history of any type of headache should be considered [26].

Given the peculiar clinical features of $\mathrm{AH}$ in the pediatric age compared to the adult population, more attention is needed towards this form of secondary headache, for better recognition even without the concomitance of other primary headaches: therefore the next edition of the ICHD should mention this entity also for the pediatric age.

\section{Conclusions}

Our study shows that $\mathrm{AH}$ is not a rare disorder in children affected by primary headaches and highlights that features of $\mathrm{AH}$ in children are peculiar and differ from those described in adults.

The exact mechanism underlying $\mathrm{AH}$ remains unclear, but it has been suggested a multifactorial pathogenesis [28].

Further studies are needed in the general pediatric population to confirm the actual frequency of $\mathrm{AH}$; in particular population-based studies might address the issue of analyzing $\mathrm{AH}$ incidence, considering a bigger sample not selected in specialized Headache Centres, with and without other concomitant headache condition, with a long-term follow-up evaluation.

\section{Abbreviations}

AH: Airplane headache; ENT: Ear, nose and throat; ICHD-III: International Classification of Headache disorders, 3rd edition

\section{Acknowledgements}

The Authors wish to thank patients and their families for their kind cooperation.

\section{Funding}

The authors have no funding to report.

\section{Availability of data and materials}

The datasets used and/or analysed during the current study (not included in this published article) are available from the corresponding author on reasonable request.

\section{Authors' contributions}

DDC: acquisition of data, analysis and interpretation of data, drafting of the manuscript. IT: design and implementation of the research, analysis of the results, drafting and revision of the manuscript. AMT, BB, MGL, LM, VR, MS, VS, AV, SZ: acquisition of clinical data, material support. SS, MG: study supervision and material support. AV, PAB: study concept and design, critical revision of the manuscript for important intellectual content. All authors read and approved the final manuscript.

\section{Ethics approval and consent to participate}

All procedures performed in the studies involving human participants were in accordance with the ethical standards of the institutional and/or national research committee and with the 1964 Helsinki Declaration and its later amendments or comparable ethical standards.

\section{Consent for publication}

For this type of retrospective study formal consent is not required.

\section{Competing interests}

The authors declare that they have no competing interests.

\section{Publisher's Note}

Springer Nature remains neutral with regard to jurisdictional claims in published maps and institutional affiliations.

\section{Author details}

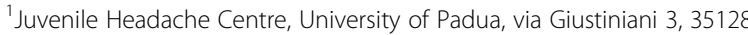
Padua, Italy. ${ }^{2}$ ''Aquila, Department of Pediatrics, San Salvatore Hospital, University of L'Aquila, L'Aquila, Italy. ${ }^{3}$ Department of Child and Adolescent Neuropsychiatry, University Hospital of Cagliari, Cagliari, Italy. ${ }^{4}$ Child Neuropsychiatry Unit, Department of Neuroscience and Sense Organs, University of "Aldo Moro" Bari, Bari, Italy. ${ }^{5}$ Child Neuropsychiatry Unit, Di Cristina Hospital, ARNAS civico, Palermo, Italy. ${ }^{6}$ Department of Child Neuropsychiatry, Università degli Studi di Bologna Scuola di Medicina e Chirurgia, Bologna, Italy. ${ }^{7}$ Neurologic and Psychiatric Sciences Department, Ist Neurological Clinic, Bari, Italy. ${ }^{8}$ Department of Child Neuropsychiatry, Università degli Studi di Palermo, Palermo, Italy. ${ }^{9}$ RCCS "La Nostra Famiglia E. Medea", Pasian di Prato, Udine, Italy.

Received: 16 September 2018 Accepted: 30 October 2018 Published online: 14 November 2018

\section{References}

1. Strine TW, Okoro CA, McGuire LC et al (2006) The associations among childhood headaches, emotional and behavioral difficulties, and health care. Pediatrics 117:1728-1735

2. Brenner M, Oakley C, Lewis D (2008) The evaluation of children and adolescents with headache. Curr Pain Headache Rep 12:361-366

3. Titlić M, Demarin V (2008) Airplane headaches-two new cases and a review of the literature. Acta Med Croatica 62:229-231

4. Atkinson V, Lee L (2004) An unusual case of airplane headache. Headache 44:438-439

5. Berilgen MS, Mungen B (2011) A new type of headache, headache associated with airplane travel: preliminary diagnostic criteria and possible mechanisms of aetiopathogenesis. Cephalalgia 31:1266-1273

6. Mainardi F, Maggioni F, Lisotto C et al (2013) Diagnosis and management of headache attributed to airplane travel. Curr Neurol Neurosci Rep 13:335

7. Mainardi F, Lisotto C, Maggioni F et al (2012) Headache attributed to airplane travel ('airplane headache'): clinical profile based on a large case series. Cephalalgia 32:592-599

8. Berilgen MS, Mungen B (2006) Headache associated with airplane travel: report of six cases. Cephalalgia 26:707-711

9. Evans RW, Purdy RA, Goodman SH (2007) Airplane descent headaches, Headache 47:719-723

10. Mainardi F, Lisotto C, Maggioni F (2007) Headache attributed to airplane travel: three new cases with first report of female occurrence and classifying criteria. J Headache Pain 8(Suppl):12

11. Mainardi F, Lisotto C, Palestini C et al (2007) Headache attributed to airplane travel ('airplane headache'): first Italian case. J Headache Pain 8:196-199

12. Marchioretto F, Mainardi F, Zanchin G (2008) Airplane headache: a neurologist's personal experience. Cephalalgia 28:101 
13. Kim HJ, Cho YJ, Cho JY et al (2008) Severe jabbing headache associated with airplane travel. Can J Neurol Sci 35:267-268

14. Coutinho E, Pereira-Monteiro J (2008) 'Bad trips': airplane headache not just in airplanes? Cephalalgia 28:986-987

15. Baldacci F, Lucetti C, Cipriani G et al (2010) Airplane headache' with aura. Cephalalgia 30:624-625

16. Kararizou E, Anagnostou E, Paraskevas GP et al (2011) Headache during airplane travel ("airplane headache"): first case in Greece. J Headache Pain 12:489-491

17. Cherian A, Mathew M, lype T et al (2013) Headache associated with airplane travel: a rare entity. Neurol India 61:164-166

18. Bui SB, Petersen T, Poulsen JN et al (2016) Headaches attributed to airplane travel: a Danish survey. J Headache Pain 17:50

19. Mainardi F, Maggioni F, Lisotto C, Zanchin G (2015) Should aircrafts never land? Headache attributed to airplane travel: a new series of 140 patients. J Headache Pain 16(suppl1):166

20. Purdy RA (2012) Airplane headache-an entity whose time has come to fly? Cephalalgia 32:587-588

21. Bui SB, Gazerani P (2017) Headache attributed to airplane travel: diagnosis, pathophysiology and treatment - a systematic review. J Headache Pain 18:1-14

22. Nierenburg H, Jackfert K (2018) Headache attributed to airplane travel: a review of literature. Curr Pain Headache Rep 22:48

23. Mainardi F, Broekmann R, Lisotto C, Maggioni F, Mampreso E, Zanchin G (2008) "Airplane headache" may occur in paediatric age: description of the first case. J Headache Pain 9:42

24. Ipekdal H, Karadas O, Erdem G (2010) Airplane headache in pediatric age group: report of three cases. J Headache Pain 11:533-534

25. Rogers K, Rafiq N, Prabhakar P et al (2015) Childhood headache attributed to airplane travel: a case report. J Child Neurol 30:764-766

26. Ozge A, Abu-Arafeh I, Gelfand AA et al (2017) Experts' opinion about the pediatric secondary headache diagnostic criteria of ICHD-III beta. J Headache Pain 18:113

27. Headache Classification Committee of the International Headache Society (IHS) (2018) The international classification of headache disorders, 3rd edition. Cephalalgia 38(1):1-211

28. Bui SBD, Petersen T, Poulsen JN et al (2017) Simulated airplane headache: a proxy towards identification of underlying mechanisms. J Headache Pain 18:1-10

Ready to submit your research? Choose BMC and benefit from:

- fast, convenient online submission

- thorough peer review by experienced researchers in your field

- rapid publication on acceptance

- support for research data, including large and complex data types

- gold Open Access which fosters wider collaboration and increased citations

- maximum visibility for your research: over $100 \mathrm{M}$ website views per year

At $\mathrm{BMC}$, research is always in progress.

Learn more biomedcentral.com/submissions 